\title{
Three-Factor and Five-Factor Models: Implementation of Fama and French Model on Market Overreaction Conditions
}

\author{
Ferikawita M. Sembiring \\ Jenderal Achmad Yani University, Bandung Indonesia
}

\begin{abstract}
Objective - Previous research by this author has stated that the market overreaction phenomenon occurs in the Indonesian capital market and the CAPM (Capital Asset Pricing Model) is able to explain portfolio returns. However, CAPM is still debated along with the emergence of the other asset pricing models, such as the multifactor model proposed by Fama and French. The aim of this research is to test the ability of that model to explain the returns of portfolios formed under market overreaction conditions.

Methodology/Technique - The data used in this study is the same as that of the previous research, which includes winner and loser portfolio data formed in market overreaction conditions, particularly on the Indonesian Stock Exchange, between July 2005 and December 2015. The multifactor models used include a three-factor model consisting of the factors of market, firm size, firm value, and a five-factor model with the added factors of profitability and investment. To obtain more accurate results, GARCH econometric models were also used in addition to standard test models for obtaining unbiased results.

Findings - This research concludes that market factors (Rm-Rf), firm size (SMB), and firm value (HML), are able to explain the winner and loser portfolio returns well. However, when the factors of profitability (RMW) and investment (CMA) are added into the three-factor model, the RMW and CMA explained the returns negatively and inconsistently when the GARCH model is implemented.
\end{abstract}

Novelty - These results imply that the three-factor model is more accurate than the five-factor model, contrary to the previous findings of Fama and French.

Type of Paper: Empirical.

Keywords: Fama and French Model; Five-factor Model; Market Overreaction; Three-factor Model; Portfolio.

JEL Classification: G11, G12, G14

\section{Introduction}

Fama and French (1993) introduced the three-factor model that has a strong empirical influence on stock portfolio fluctuations.

\footnotetext{
* Paper Info: Received: September 5, 2018

Accepted: December 11, 2018

* Corresponding author: Ferikawita M. Sembiring

E-mail: ferikawita@yahoo.com

Affiliation: Jenderal Achmad Yani University, Bandung Indonesia
} 
This model explains that portfolio returns are not only influenced by market factors. Based on the results of empirical findings, Fama and French (2015) added the factors of profitability and investment into their three-factor model, which is now known as the five-factor model. The addition of these factors refers to the model developed by Miller and Modigliani (1961) and the findings of Gibbons et al. (1989), Hou et al. (2012), Novy-Marx (2013), and Aharoni et al. (2013). Fama and French (2015) found that the five-factor model is better than three-factor model in explaining portfolio return, even though the value factor becomes redundant.

Sembiring et al. $(2016,2017)$ have also conducted research to test the effect of market risk factors on the return of stock portfolios on the Indonesian Stock Exchange. The market conditions used in that research is market overreaction conditions. The results of that research conclude that the CAPM model, specifically the CAPM conditional (dual beta) considering up-market and down-market conditions, is better able to explain returns. These results support the findings of Sharpe (1964) and Pettengill et al. (1995). However, in relation to the emergence of multifactor models that tend to oppose the accuracy of CAPM, this research will test Fama and French's multifactor model in explaining return fluctuations of stock portfolios in market overreaction conditions.

Based on the description above, this research aims at determining the performance of the three-factor and five-factor models, to determine whether the five-factor model is better than the three-factor model.

\section{Literature}

The basic assumption about the multifactor model is that returns are affected by many risk factors. The framework of the multifactor model assumes that idiosyncratic risk can be diversified and a portfolio with a zero systematic risk is a risk-free asset level, as stated in the CAPM. However, CAPM defines risk as the beta of the market portfolio while the multifactor model defines risk as the beta of several factors.

Fama and French (1993) developed a multifactor model based on observations when stocks on the US market were selected by their size and book to market ratio. Small capitalized stocks with high BE/ME ratio (also known as value stocks) were found to have higher average returns than large capitalized stocks with low BE/ME ratio (also known as growth stocks). Based on the observations that have been made, Fama and French (1993) introduced a three-factor model consisting of: market portfolio; the difference of return of small capitalized stock and a large capitalized stock (small minus big, SMB) and the difference in returns of stocks with a high BE/ME ratio and a low BE/ME ratio. The three-factor model states that the expected return for each portfolio is explained by the sensitivity of portfolio returns to market portfolio returns, SMB, and HML, with the direction of a positive relationship.

Fama and French (2015) added the factors of profitability and investment into the three-factor model, which is now referred to as the five-factor model. The addition of these factors refers to research by Miller and Modigliani (1961), Chen et al. (2011), Hou et al. (2012, Novy-Marx (2013), and Aharoni et al. (2013). Chen et al. (2011) proposes an alternative model to explain asset returns. Two portfolios are formed as a difference between returns: portfolios with a high profitability and low profitability and portfolios with low investment and high investment. These two additional factors have an average positive return whereby companies with lower investment and higher profits tend to provide higher stocks returns. Investment factor plays a more or less the same role as the value factor, where companies with higher growth have the potential to invest more but produce lower returns. Novy-Marx (2013) determines the proxy for profitability and identifies a strong relationship between profitability and average return. Meanwhile, Aharoni et al. (2013) found a weak but reliable relationship between investment and average return. Based on those empirical findings, Fama and French (2015) then added the factors of profitability and investment into the three-factor model. Fama and French (2015) conclude that the five-factor model is more successful than the three-factor model. However, the addition of profitability and investment factors renders the value factor (book to market ratio or $\mathrm{BE} / \mathrm{ME}$ ratio) of the three-factor model redundant in explaining average return. 


\section{Method}

This research uses the same sample as the author's previous research, which includes the stocks of nonfinancial sectors that effectively operate on the Indonesian Stock Exchange between July 2005 and December 2015. Based on the method proposed by De Bondt and Thaler (1985), all stock falls into either a winner or loser portfolio, totaling 20 portfolios each (Sembiring, et al., 2016). To obtain more accurate results, the stationary data test and the classical assumption test were conducted. The regression process using the heteroscedasticity conditional model (ARCH/GARCH model) was also conducted to optimize the accuracy of the research results.

The market factor value ( $\mathrm{Rm}$ - Rf) was based on the CAPM model, whereas the value of factors other than the market factor were based on the Fama and French models. The following procedures were used:

1. Sorting stocks into winner and loser portfolios based on firm size, which was indicated by market capitalization value. As many as $50 \%$ of the stocks with the largest market capitalization were set as the big firms (B) and the remaining 50\% were set as the small firms (S).

2. Sorting stocks into winner and loser portfolios based on book to market ratio (BE/ME ratio), from the lowest to the highest. Stocks with negative BE/ME ratios were rejected from the calculation. Furthermore, $30 \%$ of the stocks with highest BE/ME ratios were determined as high-value $(\mathrm{H}), 40 \%$ were determined as medium-value (M), and the remaining $30 \%$ were determined as low-value (L).

3. Establishing six portfolios based on a combination of values group, which were SL, SM, SH, BL, $\mathrm{BM}$, and $\mathrm{BH}$. Then, counting the monthly return of each portfolio, which was the average return of each stock in the portfolio.

4. Calculating the SMB and HML returns. The SMB was the difference between the average monthly return of three small portfolios (SL, SM, and $\mathrm{SH}$ ) and three big portfolios (BL, BM, and $\mathrm{BH}$ ), using the formula:

$$
\text { Return SMB }=\frac{(\mathrm{SL}+\mathrm{SM}+\mathrm{SH})-(\mathrm{BL}+\mathrm{BM}+\mathrm{BH})]}{3}
$$

The HML was the difference between the average monthly return of two high portfolios ( $\mathrm{SH}, \mathrm{BH})$ and two low portfolios (SL, BL), using the formula:

$$
\text { Return HML }=\frac{(\mathrm{SH}+\mathrm{BH})-(\mathrm{SL}+\mathrm{BL}]}{2}
$$

5. Performing regression analysis based on the three-factor model by Fama and French, using the following formula:

$$
\mathrm{R}_{\mathrm{pt}}-\mathrm{R}_{\mathrm{ft}}=\alpha_{\mathrm{p}}+\beta_{\mathrm{p}}\left(\mathrm{R}_{\mathrm{mt}}-\mathrm{R}_{\mathrm{ft}}\right)+\mathrm{s}_{\mathrm{p}} \mathrm{SMBt}+\mathrm{h}_{\mathrm{p}} \mathrm{HML}_{\mathrm{t}}+\varepsilon_{\mathrm{pt}}
$$

6. Sorting stocks into winner and loser portfolios based on firm size and profitability, from the lowest to the highest. For profitability, 30\% of the highest profit stocks were determined as the robust (R), $40 \%$ were determined as the neutral stocks $(\mathrm{N})$, and $30 \%$ of the lowest profit stocks were determined to be weak (W).

7. Establishing six portfolios based on a combination of value groups, which were SR, SN, SW, BR, $\mathrm{BN}$, and $\mathrm{BW}$, then counting the monthly return of each portfolio.

8. Calculating the RMW return:

$$
\text { Return RMW }=\frac{(\mathrm{SR}+\mathrm{BR})-(\mathrm{SW}+\mathrm{BW}]}{2}
$$


9. Sorting stocks into winner and loser portfolios and sorting stocks based on firm size and investment, from the lowest to the highest. For investment, $30 \%$ of high-investment stocks were determined as aggressive stocks (A), 40\% were determined as neutral stocks $(\mathrm{N})$, and $30 \%$ of low-investment stocks were determined as conservative stocks (C).

10. Establishing six portfolios based on a combination of value groups, which were SC, SN, SA, BC, $\mathrm{BN}$, and BA, then counting monthly return of each portfolio.

11. Calculating the CMA return:

$$
\text { Return } \mathrm{CMA}=\frac{(\mathrm{SC}+\mathrm{BC})-(\mathrm{SA}+\mathrm{BA}]}{2}
$$

12. Performing regression analysis based on the five-factor model by Fama and French using the following formula:

$$
\mathrm{R}_{\mathrm{pt}}-\mathrm{R}_{\mathrm{ft}}=\alpha_{\mathrm{p}}+\beta_{\mathrm{p}}\left(\mathrm{R}_{\mathrm{mt}}-\mathrm{R}_{\mathrm{ft}}\right)+\mathrm{s}_{\mathrm{p}} \mathrm{SMB}_{\mathrm{t}}+\mathrm{h}_{\mathrm{p}} \mathrm{HML}_{\mathrm{t}}+\mathrm{r}_{\mathrm{p}} \mathrm{RMW}_{\mathrm{t}}+\mathrm{c}_{\mathrm{p}} \mathrm{CMA}_{\mathrm{t}}+\varepsilon_{\mathrm{pt}}
$$

The hypothesis formulated was that market factors ( $\mathrm{Rm}-\mathrm{Rf}$ ), size (SMB), value (HML), profitability (RMW), and investment (CMA) has a positive effect on the returns of the winners and losers portfolios.

\section{Results and Discussion}

\subsection{Three-Factor Model}

In this section, the testing was conducted to determine whether the portfolio return was influenced by the market factors (Rm-Rf), firm size (SMB), and value (HML), according to the three-factor model. The test results are presented in the following table:

\begin{tabular}{|c|c|c|c|c|c|c|}
\hline \multicolumn{7}{|c|}{$\mathrm{Rpt}-\mathrm{Rft}=\alpha p+\beta p(\mathrm{Rmt}-\mathrm{Rft})+\mathrm{spSMBt}+\mathrm{hpHMLt}+\varepsilon p t$} \\
\hline Portfolio & $\alpha p$ & $\beta p$ & $\mathrm{sp}$ & hp & Adj. R2 & F-stat \\
\hline Winner & $0.008 * * *)$ & $0.696 * * *)$ & $0.199 * * *)$ & $0.282 * * *)$ & 0.669 & $81.093 * * *)$ \\
\hline Loser & $0.012 * * *)$ & $0.714 * * *)$ & $0.191 * * *)$ & $0.191 * * *)$ & 0.494 & $39.659 * * *)$ \\
\hline
\end{tabular}

Table 4.1 Test Results of the Three-Factor Model

***) significant at $\alpha=1 \%$

The results in Table 4.1 shows that all factors have a positive effect on portfolio return, for both the winners and losers. Then, by following the results of the classical assumption test, the regression model indicates that heteroscedasticity problems exist. Based on this, the ARCH-GARCH method was applied to the three-factor model with the following results:

Table 4.2 Test Results of the Three-Factor Model Based on GARCH (1.1)

\begin{tabular}{|c|c|c|c|c|c|c|}
\hline \multicolumn{7}{|c|}{$\mathrm{Rpt}-\mathrm{Rft}=\alpha \mathrm{p}+\mathrm{bp}(\mathrm{Rmt}-\mathrm{Rft})+\mathrm{spSMBt}+\mathrm{hpHMLt}+$ ept } \\
\hline Portfolio & $\alpha \mathrm{p}$ & $\beta \mathrm{p}$ & $\mathrm{sp}$ & $\mathrm{hp}$ & Adj. R2 & $\begin{array}{c}\text { ARCH-LM test } \\
\chi^{2}\left(\mathrm{Obs}_{*} \mathrm{R}\right.\end{array}$ \\
\hline
\end{tabular}




\begin{tabular}{|c|c|c|c|c|c|c|}
\hline & & & & & squared) \\
\hline Winner & $\mathbf{0 . 0 0 8 *})$ & $\mathbf{0 . 7 0 2} * * *)$ & $\mathbf{0 . 2 3 3} * * *)$ & $\mathbf{0 . 2 0 1} * * *)$ & 0.654 & 0.025 \\
Loser & 0.005 & $\mathbf{0 . 6 6 7 * * * )}$ & $\mathbf{0 . 1 6 3 * * * )}$ & $\mathbf{0 . 2 5 5 * * * )}$ & 0.476 & 1.926 \\
\hline
\end{tabular}

$* * *)$ significant at $\alpha=1 \%$

*) significant at $\alpha=10 \%$

Table 4.2 shows that the GARCH (1.1) model shows that the residual variant of the time series data used in the model was influenced by the residual value and residual variant value from the previous period. The test results based on the ARCH-LM method show that both models are free from heteroscedasticity.

Furthermore, when comparing the results presented in Table 4.1 and Table 4.2, the conclusions generated tended to be the same, where market (Rm-Rf), firm size (SMB), and value (HML) have a positive effect on portfolio returns, for both the winners and losers. These results are consistent with previous empirical findings, including the findings of Fama and French (1993), Wang et al. (2012), and Assefa et al. (2014).

The contrarian strategy is an investment strategy that is relevantly implemented in market overreaction conditions. The implementation of this strategy is expected to derive benefit, as shown in following table:

Table 4.3 Advantages of Contrarian Strategies Based on the Three-Factor Model

\begin{tabular}{|c|c|c|c|c|c|}
\hline Portfolio & $\alpha p$ & bp & Sp & hp & F-stat \\
\hline Loser Minus Winner & $\mathbf{0 . 0 0 4 * * )}$ & -0.010 & 0.068 & 0.045 & 0.917 \\
\hline
\end{tabular}

**) significant at $\alpha=5 \%$

Table 4.3 presents shows that the contrarian investment strategy is able to generate profit with an $\alpha p$ value indicator that is significantly positive. However, market factors, firm size, and value have no effect on the strategy.

\subsection{The Five-Factor Model}

Fama and French (2015) further state that profitability and investment also influence returns. In this section, the influence of these factors on the returns of the winner and loser portfolios is determined. The test results are presented in the following table:

Table 4.4 Test Results of the Five-Factor Model

\begin{tabular}{|c|c|c|c|c|c|c|c|c|}
\hline \multicolumn{9}{|c|}{$\mathrm{Rpt}-\mathrm{Rft}=\alpha p+b p(\mathrm{Rmt}-\mathrm{Rft})+\mathrm{spSMBt}+\mathrm{hpHMLt}+\mathrm{rpRMWt}+\mathrm{cpCMAt}+\varepsilon p t$} \\
\hline Portfolio & $\alpha p$ & $\beta \mathrm{p}$ & $\mathrm{sp}$ & hp & $\mathrm{rp}$ & $\mathrm{cp}$ & Adj. R2 & F-stat \\
\hline Winner & $\begin{array}{c}0.009 * * * \\
)\end{array}$ & $0.686 * * *)$ & $0.231 * * *)$ & $\begin{array}{c}0.204 * * * \\
)\end{array}$ & $\overline{-}^{-}$ & -0.056 & 0.686 & $\begin{array}{c}53.082 * * * * \\
)\end{array}$ \\
\hline Loser & $\begin{array}{c}0.010 * * * \\
)\end{array}$ & $0.709 * * *)$ & $0.299 * * *)$ & $0.132 * *)$ & 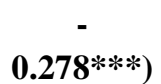 & -0.062 & 0.603 & $\begin{array}{c}37.190 * * * \\
\text { ) }\end{array}$ \\
\hline
\end{tabular}

***) significant at $\alpha=1 \%$

$* *$ ) significant at $\alpha=5 \%$ 
The results in Table 4.4 show that for both portfolios, market factors (Rm-Rf), firm size (SMB), and value (HML) have a positive effect on returns, while profitability (RMW) has a negative effect and investment was found to have no effect. This negative profitability factor implies support to the condition of reversal of return that underlies portfolio formation in market overreaction conditions.

Following the result of the classical assumption test, the regression model was indicated to contain heteroscedasticity so the ARCH-GARCH method was applied to the model with the following results:

Table 4.5 Test Results of the Five-Factor Model Based on GARCH (1.1)

\begin{tabular}{|c|c|c|c|c|c|c|c|c|}
\hline \multicolumn{9}{|c|}{$\mathrm{Rpt}-\mathrm{Rft}=\alpha \mathrm{p}+\mathrm{bp}(\mathrm{Rmt}-\mathrm{Rft})+\mathrm{spSMBt}+\mathrm{hpHMLt}+\mathrm{rpRMWt}+\mathrm{cpCMAt}+\varepsilon \mathrm{pt}$} \\
\hline $\begin{array}{c}\text { Portfoli } \\
\text { o }\end{array}$ & $\alpha p$ & $\beta p$ & $\mathrm{sp}$ & hp & $\mathrm{rp}$ & $\mathrm{cp}$ & Adj. R2 & $\begin{array}{c}\text { ARCH-LM test } \\
\chi^{2}\left(\mathrm{Obs}^{*} \mathrm{R}\right. \\
\text { squared) }\end{array}$ \\
\hline Winner & $\begin{array}{c}\mathbf{0 . 0 1 0} * * \\
*)\end{array}$ & $\begin{array}{c}\mathbf{0 . 6 6 3}^{* *} \\
*)\end{array}$ & $\begin{array}{c}\mathbf{0 . 2 7 2} \text { ** } \\
*)\end{array}$ & $\begin{array}{c}0.234 * * \\
*)\end{array}$ & 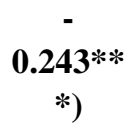 & $\begin{array}{c}- \\
0.082 * * \\
)^{2}\end{array}$ & 0.681 & 0.100 \\
\hline Loser & 0.004 & $\begin{array}{c}0.671^{* *} \\
*)\end{array}$ & $\begin{array}{c}0.193 * * \\
*)\end{array}$ & $\begin{array}{c}0.212 * * \\
*)\end{array}$ & 0.015 & $\begin{array}{c}- \\
0.092 * * \\
)\end{array}$ & 0.465 & 1.979 \\
\hline
\end{tabular}

**) significant at $\alpha=5 \%$

Furthermore, when comparing the results presented in Table 4.4 and Table 4.5, the conclusions produced tend to be the same. The difference lies in the significant investment factors in the model based on GARCH (1.1) and the insignificant profitability factor in the loser portfolio. Meanwhile, the benefit obtained by applying contrarian strategies are presented in the following table:

Table 4.6 Advantages of Contrarian Strategies Based on the Five-Factor Model

\begin{tabular}{|c|c|c|c|c|c|c|c|}
\hline Portfolio & $\alpha p$ & bp & sp & hp & rp & cp & F-stat \\
\hline $\begin{array}{c}\text { Loser Minus } \\
\text { Winner }\end{array}$ & $\mathbf{0 . 0 0 2} *)$ & -0.009 & $\mathbf{0 . 1 6 5 * * * )}$ & $\mathbf{0 . 0 5 7 * )}$ & $\mathbf{- 0 . 2 0 6 * * * )}$ & 0.023 & $8.020 * * *)$ \\
\hline$* * *$ significant at $\alpha=1 \%$ & \\
$*$ *) significant at $\alpha=10 \%$
\end{tabular}

Table 4.6 shows that contrarian investment strategies are able to generate profit with an $\alpha$ indicator that is significantly positive. All factors influence the implementation of the strategy, except for market factors and investment.

\section{Conclusion}

This research concludes that all factors in the three-factor model are able to explain the returns of both portfolios consistently when the GARCH (1.1) model is applied. Consistent results for all three factors were also obtained when profitability and investment factors were added into the model. However, there were different results for profitability and investment factors. Both of these factors were found to have a negative coefficient, in contrast to the hypothesis proposed. This negative coefficient is likely caused by the condition 
of reversal of portfolio returns that was formed based on market overreaction conditions, where the winner became the loser and vice versa during the observation period.

Furthermore, when the GARCH (1.1) model was applied to eliminate heteroscedasticity in the model, different results were also obtained. The profitability factor had no effect on the loser portfolio, while the investment factor had a significant influence on both portfolios. These results indicated that the three-factor model is more successful than the five-factor model, contrary to the findings of Fama and French (2015). This is likely due to differences in conditions in the formation of the portfolio, as previously explained.

The test results also show that size, value, and profitability influence the benefits derived from the application of contrarian strategies. This indicates the need for stakeholders to pay attention to these factors when implementing a contrarian strategy into market conditions that are assumed to overreact.

One of the limitations of the research is the inconsistency of the results. In addition to market overreaction conditions, there is also market underreaction conditions, which is not accounted for in this study.

\section{References}

Aharoni, G., Grundy B., Zeng Q. (2013). Stock Returns and the Miller Modigliani Valuation Formula: Revisiting the Fama French Analysis, Journal of Financial Economics, 110, 347-357

Assefa, Tibebe A., Esqueda, Omar A., Galariotis, Emilios C. (2014). Overreaction Evidences from Large-cap Stocks, Review of Accounting and Finance 13(4), 310-325

Chen, Long, Novy-Marx, R., Zhang, Lu (2011). An Alternative Three-factor Model, The Ohio State University and NBER working paper. 1-32.

De Bondt, Werner, F. M., Thaler, Richard (1985). Does the Stock Market Overreact? Journal of Finance, 40(3), 793805.

Fama, E. F., French, Kenneth F. (1993). Common Risk Factors in the Return on Stock and Bonds, Journal of Financial Economics, 33, 3-56.

Fama, E. F., French, Kenneth F. (2015). A Five-factor Asset Pricing Model, Journal of Financial Economics, 116, 1-2. Gibbons, M., Ross, S., Shanken, J. (1989). A Test of the Efficiency of a Given Portfolio, Econometrica, 57, 1121-1152. Hou, K., Xue, C., Zhang, L. (2012). Digesting Anomalies: An Investment Approach, NBER Working Paper No 18435. Miller, M., Modigliani, F. (1961). Dividend Policy, Growth, and the Valuation of Shares, Journal of Business, 34, 411433.

Novy-Marx, R. (2013). The Other Side of Value: The Gross Profitability Premium. Journal of Financial Economics, 108, 1-28.

Pettengil, Glenn N., Sundaram, Sridhar, Mathur, Ike (1995). The Conditional Relation Between Beta and Return, Journal of Financial and Quantitative Analysis, 30, 101-116.

Sembiring, Ferikawita M., Rahman, S., Effendi, N., Sudarsono, R. (2016). Capital Asset Pricing Model in Market Overreaction Conditions: Evidence from Indonesia Stock Exchange. Polish Journal of Management Studies, 14(2), 182 $-190$.

Sembiring, Ferikawita M., Rahman, S., Effendi, N., Sudarsono, R. (2017). Single Beta and Dual Beta Models: A Testing of CAPM on Condition of Market Overreaction. Journal of Finance and Banking Review, 2(3), 1-7.

Sharpe, William. F. (1964). Capital Asset Prices: A Theory of Market Equilibrium Under Conditions of Risk. Journal of Finance, 19, 425-442.

Wang, Ching-Ping, Huang, Hung-Hsi, Huang, Chi-Chung (2012). Momentum and Contrarian Profits Corresponding to the Coincident Economic Indicator on the Taiwan Stock Market. Emerging Markets Finance and Trade, 48, 29-40. 